\title{
Osteoclast stimulation factor 1 (Ostf1) KNOCKOUT increases trabecular bone mass in mice
}

\author{
Matthieu Vermeren ${ }^{1,5} \cdot$ Rodanthi Lyraki $^{1} \cdot$ Sachin Wani $^{1} \cdot$ Rannar Airik $^{2}$ • \\ Omar Albagha ${ }^{1} \cdot{\text { Richard } \text { Mort }^{3} \cdot \text { Friedhelm Hildebrandt }^{4} \cdot \text { Toby Hurd }}^{1,6} \mathbb{C}_{\mathbb{C}}$
}

Received: 2 August 2017 / Accepted: 14 September 2017 / Published online: 21 September 2017

(c) The Author(s) 2017. This article is an open access publication

\begin{abstract}
Osteoclast stimulation factor 1 (OSTF1) is an SH3-domain containing protein that was initially identified as a factor involved in the indirect activation of osteoclasts. It has been linked to spinal muscular atrophy in humans through its interaction with SMN1, and is one of six genes deleted in a human developmental microdeletion syndrome. To investigate the function of OSTF1, we generated an Ostf1 knockout mouse model, with exons 3 and 4 of Ostfl replaced by a LacZ orf. Extensive X-Gal staining was performed to examine the developmental and adult expression pattern, followed by phenotyping. We show widespread expression of the gene in the vasculature of most organs and in a
\end{abstract}

Electronic supplementary material The online version of this article (doi:10.1007/s00335-017-9718-3) contains supplementary material, which is available to authorised users.

Toby Hurd

Toby.Hurd@Igmm.ed.ac.uk

1 Institute for Genetics and Molecular Medicine, University of Edinburgh, Western General Hospital Campus, Crewe Road, Edinburgh EH4 2XU, UK

2 Rangos Research Center, Children's Hospital of Pittsburgh, Pittsburgh, PA 15224, USA

3 Division of Biomedical and Life Sciences, Faculty of Health and Medicine, Lancaster University, Lancaster LA1 4YG, UK

4 Division of Nephrology, Boston Children's Hospital, Harvard Medical School, Enders 561, 300 Longwood Avenue, Boston, MA 02115, USA

5 MRC Centre for Inflammation Research, Queen Medical Research Institute, University of Edinburgh, 47 Little France, Edinburgh EH16 4TJ, UK

6 MRC Human Genetics Unit, Institute for Genetics and Molecular Medicine, University of Edinburgh, Edinburgh, UK number of cell types in adult and embryonic mouse tissues. Furthermore, whilst SHIRPA testing revealed no behavioural defects, we demonstrate increased trabecular mass in the long bones, confirming a role for OSTF1 in bone development.

\section{Introduction}

Osteoclast stimulation factor 1 (OSTF1) was originally described as SH3P2 in a screen for Src-homology 3 (SH3)containing proteins by peptide array (Sparks et al. 1996), and independently also discovered in an expression cloning screen (Reddy et al. 1998). OSTF1 indirectly enhances, through the supernatant of transfected 293 cells, osteoclast formation and bone-resorption activity in cell culture assays. Structurally, OSTF1 is a small intracellular protein that contains an SH3 domain closely followed by four ankyrin domains (Tong et al. 2009). Northern blot analysis indicated the presence of a single $O S T F 1$ transcript in multiple human tissues (Reddy et al. 1998). In a series of cell-based experiments, overexpression of OSTF1 in HeLa cells was found to have a negative impact on cell motility in transwell migration assays (Tanimura et al. 2011). Morphologically, these transfected HeLa cells were found to be more rounded and had a smaller footprint that controls.

OSTF1 has been shown to interact directly with a series of intracellular proteins using several methods, including co-immunoprecipitation, peptide array and yeast two hybrid. Binding partners identified include F-actin (Szymkiewicz et al. 2004), the non-receptor tyrosine kinase c-Src (Reddy et al. 1998; Szymkiewicz et al. 2004) and the E3 ubiquitin-protein ligase Casitas B-lineage lymphoma (Cbl) (Szymkiewicz et al. 2004; Vinayagam et al. 2011). This specific interaction has been shown to be strengthened by the 
co-localisation of OSTF1 with Cbl in the podosomes of osteoclast-like cells, and has been suggested to be important for their bone-resorption properties (Szymkiewicz et al. 2004). OSTF1 has also been demonstrated to interact with Survival of Motor Neuron 1 and 2 (SMN1 and SMN2 respectively) (Kurihara et al. 2001; Vinayagam et al. 2011), the loss of which leads to spinal muscular atrophy. Both SMN1- and -2 are found in the cytoplasm of neurons from which they translocate to subnuclear bodies called gems, where small nuclear riboproteins are assembled (Massenet et al. 2002; Paushkin et al. 2002). Intriguingly, conditioned media from 293 cells overexpressing SMN has also been shown to drive enhanced formation and hyper-activation of osteoclasts (Kurihara et al. 2001).

Together with three other known genes and two open reading frames of unknown functions, OSTF1 forms part of a chromosomal region that is deleted in a microdeletion syndrome at 9q21.13 (Baglietto et al. 2014; Boudry-Labis et al. 2013). The deletion leads to mild mental retardation, autism-spectrum disorder, small stature, speech delay and epileptic seizures. OSTF1 is thought to play only a minor role in this syndrome since the mouse knockout of two of the deleted genes, the retinoic acid receptor RAR-related Orphan Receptor B (RORB) and the magnesium channel Transient Receptor Potential cation channel, subfamily M, member 6 (TRPM6) recapitulate some of the syndrome's phenotypes (Boudry-Labis et al. 2013). No knockout of the fourth gene in the deletion, Nicotinamide Riboside Kinase 1 (NMRK1) has been reported.

Genome wide association studies correlate variation in OSTF 1 to coronary artery diseases, variation in body mass index (Fox et al. 2007), Alzheimer's disease (Furney et al. 2011), multiple sclerosis (Baranzini et al. 2009) and nonalcoholic fatty liver disease (Chalasani et al. 2010). However, correlation is not causation and the in vivo function of OSTF1 remains unknown.

Here, we report for the first time a mouse knockout for

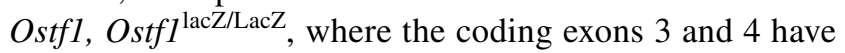
been replaced by the LacZ reporter. We observe that the Ostf $1^{\text {lacZ/LacZ }}$ mouse suffers from a mild form of osteopetrosis, caused by an increase in trabecular bone. We have taken advantage of the LacZ insertion and extensively analysed the expression pattern of Ostfl through X-Gal staining and defined further regions of potential interest for phenotyping.

\section{Materials and methods}

\section{Accession IDs}

Organism (mouse)-Taxon ID 10090. Gene (Ostfl)—Gene ID 20409.

\section{OSTF1 $^{+/ \text {LacZ }}$ mice}

ES cells on the C57BL/6N background for the Ostf $1^{\text {tm1(NCOM)Cmhd }}$ mouse, termed Ostf $1^{\text {LacZ }}$ line in this paper are available from NorCOMM under the ID NO1551. Chimeric mice were prepared by blastocyst microinjection and bred with C57BL/6J mice to obtain germline transmission. All experimental procedures using animals were approved by The University of Edinburgh's Animal Welfare and Ethical Review Board and conducted under the Animals (Scientific Procedures) Act 1986. All work was performed under project licence \#60/4424. All mice used in this study were euthanized by $\mathrm{CO}_{2}$ inhalation.

\section{Western blotting}

Western blotting was done using standard procedures. The following primary antibodies were used: rabbit antiOSTF1 (Bethyl laboratories, A303-004A) at 1:10,000 dilution (Fig. 1a, g, f), rabbit anti-OSTF1 (Atlas HPA020514) at 1:200 dilution (Fig. 1b), rabbit anti- $\beta$ actin (Neomarkers RB-9421-R1) at 1:100 dilution, rabbit anti- $\beta$ galactosidase (Invitrogen A-11132) at 1:5000 dilution.
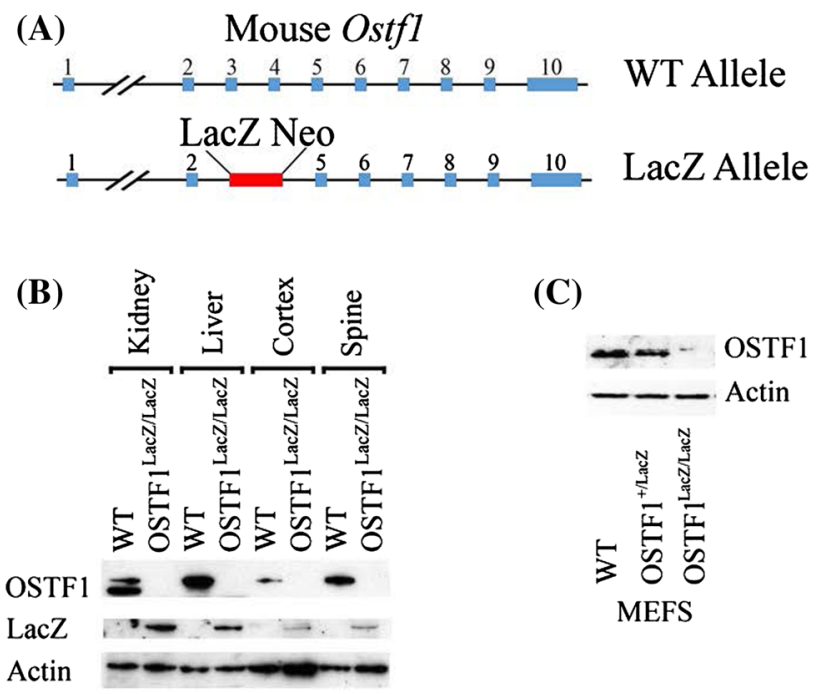

(C)

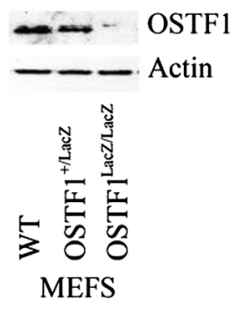

Fig. 1 The $O s t f l^{\text {LacZ/LacZ }}$ mouse is a knockout with $\beta$-galactosidase activity reflecting levels of Ostfl expression. a Gene knockout strategy: out of 10 exons (blue boxes), exons 3 and 4 are replaced by a LacZ Neo cassette (red). b Western blotting to detect endogenous OSTF1 in different tissues. OSTF1 protein expression is observed in wild-type kidney, liver, cortex and spine, but absent in $\operatorname{Ostf}_{1}{ }^{\mathrm{LacZ} / \mathrm{LacZ}}$ tissues. $\beta$-galactosidase ( $\mathrm{LacZ}$ ) protein expression is only detected in $O s t f 1^{\text {LacZ/LacZ }}$ tissues. $\beta$-actin was used as a loading control. c Expression of OSTF1 in lysates from MEFs derived from wild type (WT), Ostf $1^{+/ \text {LacZ }}$ and Ostf $1^{\text {LacZ/LacZ }}$ mice. $\beta$-actin was used as a loading control 


\section{Genotyping}

DNA was extracted from fresh tissue, amplified by PCR and products resolved by gel electrophoresis. Primers used were: Exon 3F AACCACCACTGTATTCTAAGGTAGG, Exon 3R AAACAGTCCAGCACTATGCTAATC, Exon 4F CGGACCCAGATGGTTTCAG, Exon 4R CGTGCGTTT GTCCTGTTG, Exon 9F TTGTTCTCCGGTAGCTTTGC, Exon 9R CTCGCCCTTTGCAGTAAAAC, LacZ F ATC CTCTGCATGGTCAGGTC, LacZ R CGTGGCCTGATT CATTCC. PCR conditions are available upon request.

\section{LacZ staining}

Otherwise mentioned, all products were obtained from Sigma. Tissues were processed for cryostat sectioning followed by X-Gal staining according to standard procedures (Mackenzie et al. 1997). Some sections were counterstained with eosin.

\section{Generation of mouse embryonic fibroblasts (MEFs)}

MEFs were generated from E13 embryos according to standard procedures and cultured in Optimem supplemented with $10 \%$ foetal bovine serum, penicillin/streptomycin and $114 \mu \mathrm{M} \beta$-mercaptoethanol. After three passages, MEFS were processed either for X-Gal staining or for protein extraction.

\section{Imaging}

Stained sections were photographed with an upright AX10 microscope (Zeiss) linked to a Retiga 400R camera (QImaging) using a QImagin pluggin for ImageJ/FiJi. Images were processed and assembled using Adobe Photoshop. Some sections were photographed using a Dotslide scanner (Olympus) and images were analysed using the OlyVia software (Olympus).

\section{CT scanning and bone analysis}

Legs of age-matched male WT and Ostfl ${ }^{\text {lacZ/LacZ mice }}$ were isolated and fixed overnight in $4 \%$ paraformaldehyde. Muscles were then dissected out and the entire leg was stored in 70\% ethanol. Scanning was performed on a Skyscan 1172 Micro-CT scanner (Bruker, Kontich, Belgium) following the protocol described in van't Hof and Ralston (1997) and van't Hof (2012). Data was then reconstructed and a slice of bone below the growth plate was selected for quantification as described in Idris et al. (2005).

\section{Osteoclast differentiation}

Legs of age-matched male WT and Ostf1 ${ }^{\text {lacZ/LacZ }}$ sibling mice were isolated. Bone marrow from tibia and femurs were expelled from bone shafts using a MEM-containing syringe and 23 gauge needle. Subsequently, bone marrow was triturated to dissociate the cells and then plated in MEM/ FCS/Pen-Strep/Glutamine containing macrophage colony stimulating factor (M-CSF, $100 \mathrm{ng} / \mathrm{ml}$, Prospec) to induce macrophage production. After 2 days, M-CSF dependent macrophages were dissociated and 5000 cells were put in each well of a Lab-Tek multichamber. Medium was then changed to MEM/FCS/Pen-Strep/Glutamine containing $25 \mathrm{ng} / \mathrm{ml}$ of M-CSF and $100 \mathrm{ng} / \mathrm{ml}$ of Receptor activator of nuclear factor kappa-B ligand (RANKL, Prospec) to induce osteoclast differentiation. Cells were left to differentiate for 5 days before processing.

\section{Tartrate resistant acid phosphatase (TRAP) staining}

Fixed osteoclast cultures were TRAP stained according to protocol described in (Idris et al. 2005). Chamber slides containing osteoclasts were photographed with an inverted microscope (Zeiss) and multinucleate TRAP-positive osteoclasts were manually counted.

\section{Identification of OSTF1-interacting proteins}

To identify OSTF1-interacting proteins, HEK293 cells cultured in DMEM/10\% FCS/Pen-Strep were transiently transfected in triplicate with either empty vector (pCDNA3.1 V5-His) or V5-OSTF1 plasmids. After $48 \mathrm{~h}$, cells were lysed in IP lysis buffer (50 mM Tris $\mathrm{pH} 7.5,1 \%$ Triton-X100, $150 \mathrm{mM} \mathrm{NaCl}$ ), protein content measured and subjected to automated IP on a Kingfisher Duo (Thermo) using anti-V5 magnetic agarose (MBL). Digestion and protein identification was performed by the MRC Institute of Genetics \& Molecular Medicine Proteomics Facility.

\section{Behaviour analysis}

Mice tested were age-matched siblings from heterozygotous pairing. Cohorts consisted of six female WT, seven female heterozygotes and six female $O s t f I^{\mathrm{LacZ} / \mathrm{LacZ}}$, four male WT, three male heterozygotes and eight male $\operatorname{Ostf} I^{\text {LacZ/LacZ }}$.

1. SHIRPA test was as described in Rogers et al. (1997)

2. Cat Box test: In order to analyse movement and gait, we constructed a $1 \mathrm{~m}$-long, $10 \mathrm{~cm}$ wide and $20 \mathrm{~cm}$ high Perspex box with a translucent floor located mid-height, 
Fig. 2 OSTF1 is widely expressed in brain tissue. a Tissues belonging to the nervous system were dissected and subjected to western blotting using an anti-OSTF1 antibody with $\beta$-actin serving as loading control. RPE retinal pigmented epithelium. b The parabrachial nucleus expresses the highest level of OSTF1 (arrow). $\mathbf{c}-\mathbf{g}$ OSTF1 is found at low level in the hippocampal formation. d OSTF1 expression appears as puncta in the subiculum. e OSTF1 expression in the polymorph layer of the dentate gyrus (DG). f, $\mathbf{g}$ The cornus amonis (CA) region 2 (CA2) defined by dashed lines between $\mathrm{CA} 1$ and CA3. $\mathbf{h}, \mathbf{i}$ In the cortex of the cerebellum (panel $\mathbf{h}$ ), OSTF1 is only found in blood vessels (arrowhead) but it is consistently present in the deep cerebellar nuclei (panel $\mathbf{i}$-arrow). j, k Small puncta indicate low levels of expression in the mammillary nucleus (panel $\mathbf{j}$-arrow) and the spinal vestibular nucleus (panel $\mathbf{k}$-arrow). $\mathbf{k}$ The ventricular surface (white arrow) and the choroid plexus (red arrow) both express OSTF1. I, m Throughout the brain, OSTF1 is highly expressed by the endothelium of the blood vessels (black arrowheads) as exemplified by large and small blood vessels in panel $\mathbf{k}, \mathbf{I}$ and in small branched cells. n, p In the E14 embryo head, OSTF1 expression was observed in the blood vessels and the meninges (dark arrowheads). n OSTF1 is, however, also present in the cartilage precursor of the skull (arrows). o At this stage, the trigeminal neurons express varying levels of OSTF1. $\mathbf{p}$ In contrast, the spiral ganglia express high levels of OSTF1 and the epithelium of the cochlear epithelium (notched arrowhead). Scale bar $=500 \mu \mathrm{m}$, all other panels scale bar $=100 \mu \mathrm{m}$
(A)
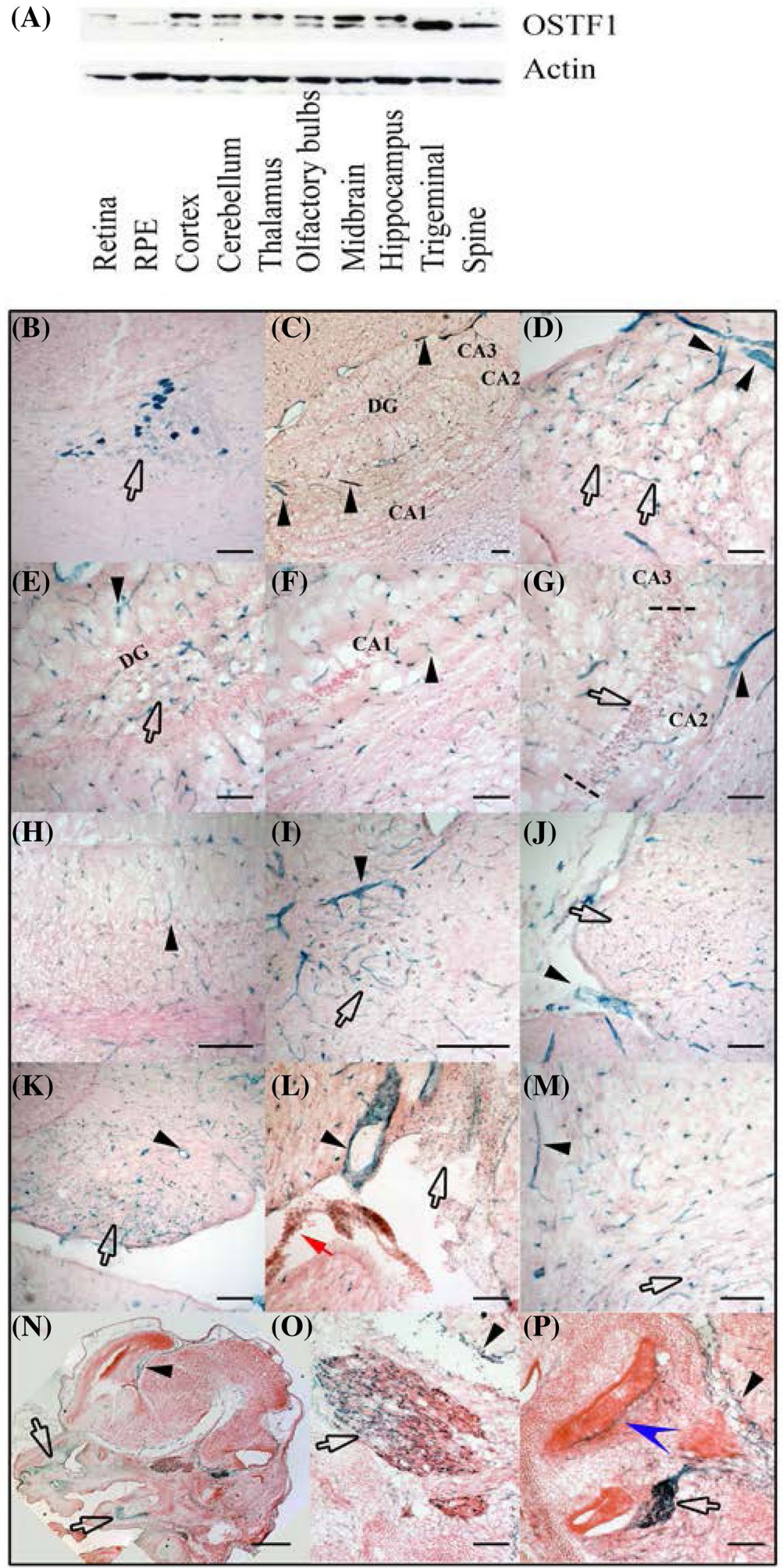
$10 \mathrm{~cm}$ from the base. A $45^{\circ}$ angle mirror was placed under the floor so that the mouse could be observed from the side and from underneath at the same time. Mice were allowed to run the length of the box to a cardboard tube while being filmed using a Canon S500 SLR camera. Movies were converted to the AVI format using Avidemux (http://www.avidemux.org/admWiki/doku. php) before being imported into ImageJ/Fiji (Schneider et al. 2012). A custom macro was then used to record the positions at which each paw made contact with the floor. Step size was measured using Pythagoras' theorem.

3. Food burrowing test was as described in Yang and Crawley (2009)

4. Preyer's reflex: We have constructed a click box (https:// www.ihr.mrc.ac.uk/projects/clickBox). Preyer's reflex was tested by clicking once near the tested animal and observing whether its ears twitched.

\section{Results}

\section{$O s t f 1^{L a c Z / L a c Z}$ is a knockout for Ostf1}

We took advantage of the availability of an Ostf1 mouse ES cells, Ostf $1^{\text {LacZ/LacZ }}$, from the North American Conditional Mouse Mutagenesis Project (Fig. 1a). In these mice, exons 3 and 4 that encode most of the Ostf1 SH3 domain are replaced by a LacZ expression cassette. As a result, the remaining exons are out of frame. As expected, OSTF1 protein was undetectable by Western blotting in Ostfl ${ }^{\text {lacZI }}$ LacZ tissues (Fig. 1b). Instead, LacZ was expressed under
Table 1 Table summarising expression pattern of OSTF1 in the adult mouse brain

\begin{tabular}{|c|c|c|}
\hline Main structure & Structure & $\begin{array}{l}\text { Level of } \\
\text { expres- } \\
\text { sion }\end{array}$ \\
\hline \multirow[t]{2}{*}{ Everywhere } & Blood vessels & 3 \\
\hline & Pial surface & 2 \\
\hline Cortex & Somatosensory, layer V & 1 \\
\hline \multirow[t]{3}{*}{ Hippocampal formation } & $\mathrm{CA} 2$ & 1 \\
\hline & Polymorph region of dentate gyrus & 1 \\
\hline & Subiculum & 1 \\
\hline \multirow[t]{3}{*}{ Thalamus } & Submedial nucleus of the thalamus & 1 \\
\hline & Reticular nucleus of the thalamus & 1 \\
\hline & Mediodorsal nucleus of the thalamus & 1 \\
\hline Hypothalamus & Mammillary nucleus & 1 \\
\hline Striatum & Amygdalar nuclei & 1 \\
\hline \multirow[t]{2}{*}{ Midbrain } & Red nucleus & 1 \\
\hline & Oculomotor nucleus & 1 \\
\hline Cerebellum & Deep cerebellar nuclei & 1 \\
\hline \multirow[t]{11}{*}{ Hindbrain } & Pontine gray & 1 \\
\hline & Pontine reticular nucleus & 1 \\
\hline & Superior olivary complex & 1 \\
\hline & Tegmental reticular nucleus & 1 \\
\hline & Dorsal nucleus raphe & 3 \\
\hline & Medial vestibular nucleus & 1 \\
\hline & Dorsal cochlear nucleus & 1 \\
\hline & Nucleus of the lateral lemniscus & 1 \\
\hline & Primary sensory nucleus of the trigeminal & 1 \\
\hline & Spinal vestibular nucleus & 1 \\
\hline & Paragigantocellular reticular nucleus & 2 \\
\hline \multirow[t]{3}{*}{ Spinal cord } & Motor neurons & 1 \\
\hline & Floor plate & 1 \\
\hline & Central canal & 1 \\
\hline DRGs & Salt and pepper in all sensory neurons & $2-3$ \\
\hline \multirow[t]{2}{*}{ Cranial ganglia } & Trigeminal & 3 \\
\hline & Vestibulocochlear ganglia & 3 \\
\hline
\end{tabular}


the control of Ostfl promoter (Fig. 1b). Similarly, reduction and loss of OSTF1 protein was also observed in embryonic fibroblasts derived from $O s t f I^{+/ \mathrm{LacZ}}$ and $O s t f I^{\text {lacZ/LacZ }}$ animals, respectively (Fig. 1c).

Heterozygous mating yielded 151 mice at the ratio of, 40 wild types: 63 heterozygotes: 48 knockouts. Both male and female homozygous $O s t f I^{\text {lacZ/LacZ }}$ mice were fertile and without overt deleterious phenotype up until the age of 1 year.

\section{Ostf1 expression}

In order to define potential function of the Ostfl, the spatial and temporal pattern of expression was examined through the use of a combination of X-Gal staining, Western blotting and RT-PCR. X-Gal staining was used extensively since it allows for resolution of expression at the single cell level.

\section{Central nervous system}

Unlike the recently assumed (Baglietto et al. 2014; BoudryLabis et al. 2013) and in keeping with the original findings of Reddy et al. (1998), we find that Ostfl is widely expressed in the brain, albeit at low levels. Western blotting revealed Ostfl expression in virtually all central nervous system regions' analyses, albeit at differing levels (Fig. 2a). Results are summarised in Table 1. The highest level of expression was noted in the neurons of the parabrachial nucleus (Fig. 2b, arrow). Together with axons from the cranial ganglia, the parabrachial nucleus neurons were the only ones to sport neurites that were also clearly labelled. In other regions, LacZ was expressed far more weakly, suggesting that less Ostfl is normally expressed. For example, we observed Ostfl expression in the hippocampal formation (Fig. 2c): in the subiculum (Fig. 2d, arrows), polymorph region of the dentate gyrus (Fig. 2e, DG, arrow), Cornus Amonis region 2 (CA2) (Fig. 2g, arrow, defined by dashed line) but neither CA1 or CA3 (Fig. 2f, g). In the cerebellum, Ostfl was restricted to blood vessels in the cortex (Fig. 2h, black arrow head) and it was observed as small puncta in the neurons of the deep cerebellar nuclei (Fig. 2i, arrow). Ostf1 was also expressed in the mammilary nucleus and the spinal vestibular nucleus (Fig. 2j, k respectively).

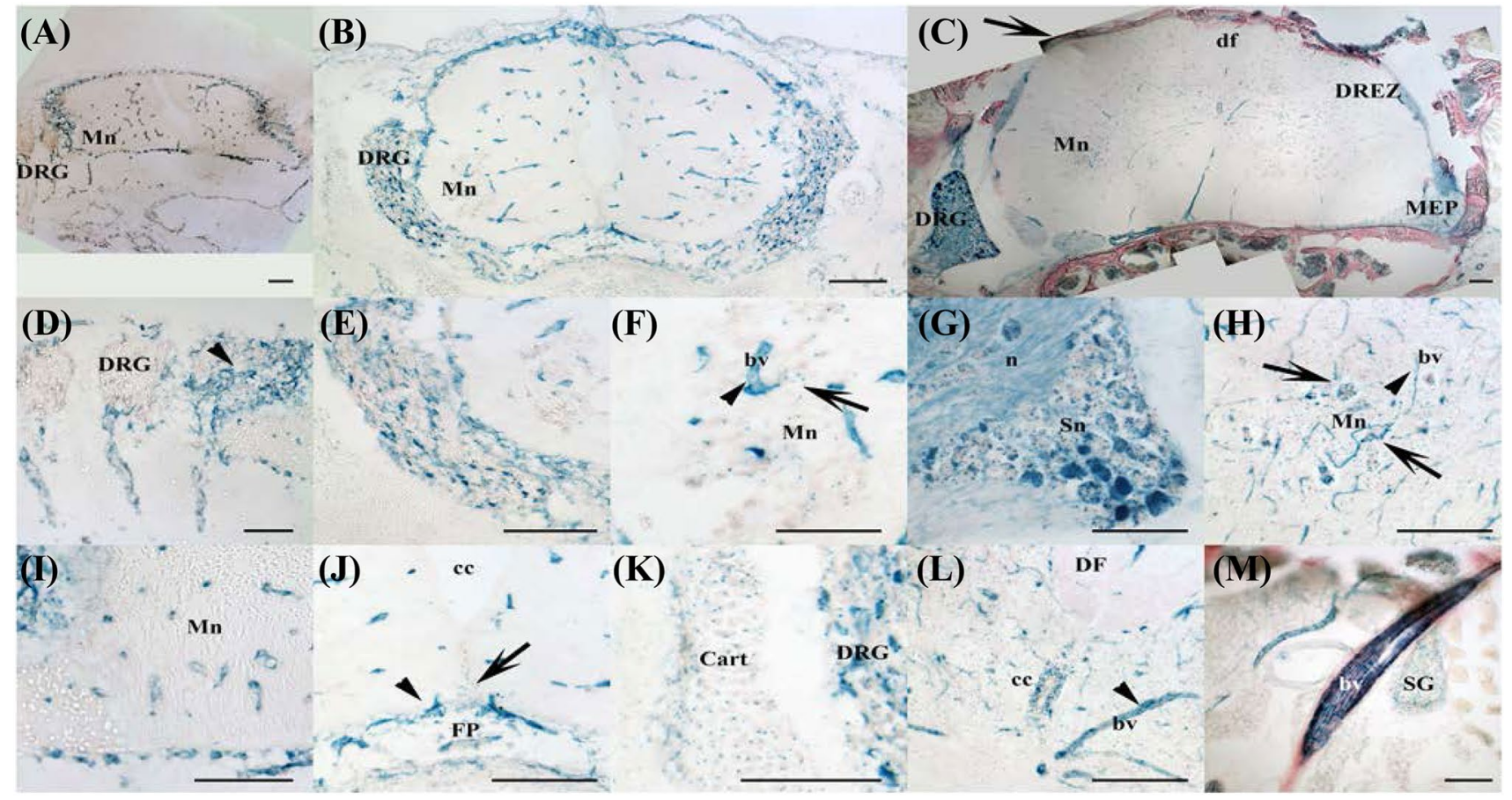

Fig. 3 OSTF1 is widely expressed in the spinal cord and dorsal root ganglia (DRGs). a-c At E10, OSTF1 is found exclusively in the developing capillary network of the spine (panel a), surrounding OSFT1-negative DRGS (panel b) and motor neurons (panel c, Mn). d-h Strong expression in the blood vessels (bv and dark arrowheads) at E15. The neurons of the DRGs start expressing OSTF1 (panel e) at E15. It is at that stage that motor neurons (panel $\mathbf{f}$ ) begin expressing OSTF1. $g$ The floor plate (FP) but not the central canal (cc) express OSTF1. h The cartilage surrounding the spine expresses low levels of OSTF1. i-m Expression in the blood vessels (bv and dark arrow- heads) in adult mice. $\mathbf{i}, \mathbf{j}$ In the adult mouse, all DRG neurons express OSTF1, albeit at different levels, the signal is not restricted to the cell bodies and can be found in the neurites (n) of the dorsal roots to the Dorsal Root Entry Zone (DREZ) and the distal part of the dorsal funiculus (arrow in panel $\mathbf{i}, \mathrm{df}$ ) as well as at the Motor Exit Point (MEP). $\mathbf{k}$ Expression of OSTF1 in the motor neurons (arrows) is well established. I Likewise, OSTF1 is found in the central canal (cc). m Low level of OSTF1 is detected in the sympathetic ganglia (SG). Scale bars $=100 \mu \mathrm{m}$ 
Throughout the brain, large and also small blood vessels were strongly labelled (dark arrowheads exemplified in Fig. 21, m). Likewise, the lining of the brain, the ventricles as well as the choroid plexus (Fig. 21, white and red arrows) were LacZ positive. Finally, everywhere except in the cerebellum, small branched cells, presumably oligodendrocytes and their precursors were observed to express OstfI (Fig. 2m).

In the spinal cord as in the brain, the capillary network was strongly LacZ positive as early as at E11, (Fig. 3a-c, arrowheads), at E14 and in adult tissues (Fig. 3d, i respectively). Noticeably, motor neurons expressed low levels of Ostf1 from E14 until adulthood (Fig. 3b, e, k, arrows). At E14, the floor plate was observed to express low levels of Ostfl (Fig. 3g, FP) but this was no longer seen in the adult. In contrast, in the adult spine, the ependymal cells of the central canal were also LacZ positive (Fig. 31, cc), while these structures were not LacZ positive in E14 and E11 spines (Fig. 3g, cc).

\section{Peripheral nervous system}

Both trigeminal ganglia (Fig. 2o, arrow) and spiral ganglia (Fig. 2p, arrow) expressed high levels of OSTF1. While all the neurons of the spiral ganglia were LacZ positive at E14, expression was initially non-uniform in trigeminal neurons. In contrast, in the adult mouse, all neurons strongly expressed LacZ.

LacZ was detected in the sensory neurons of the Dorsal Root Ganglia (DRGs) from E14 onwards (Fig. 3a, b, d, e, respectively) when DRGS were composed of neurons expressing no, weak or strong OSTF1 expression. In adult DRGs, all neurons express Ostf1 to some degree (Fig. 3i, j), indicating that Ostfl expression varies between different types of sensory neuron and their developmental stage. This was further supported by the mixture of LacZ positive and negative axons present in sensory nerves (Fig. 3J, n) near the DRGs and at Dorsal Root Entry Zone (DREZ) level (Fig. 3i, DREZ). Given the lateral position of the LacZ positive axon bundles in the dorsal funiculus (df), it appears likely that the DRG neurons which express high levels of Ostf1 are nociceptors (Fig. 3i, arrow). In contrast, Ostfl signal in the sympathetic ganglia (Fig. 3m,

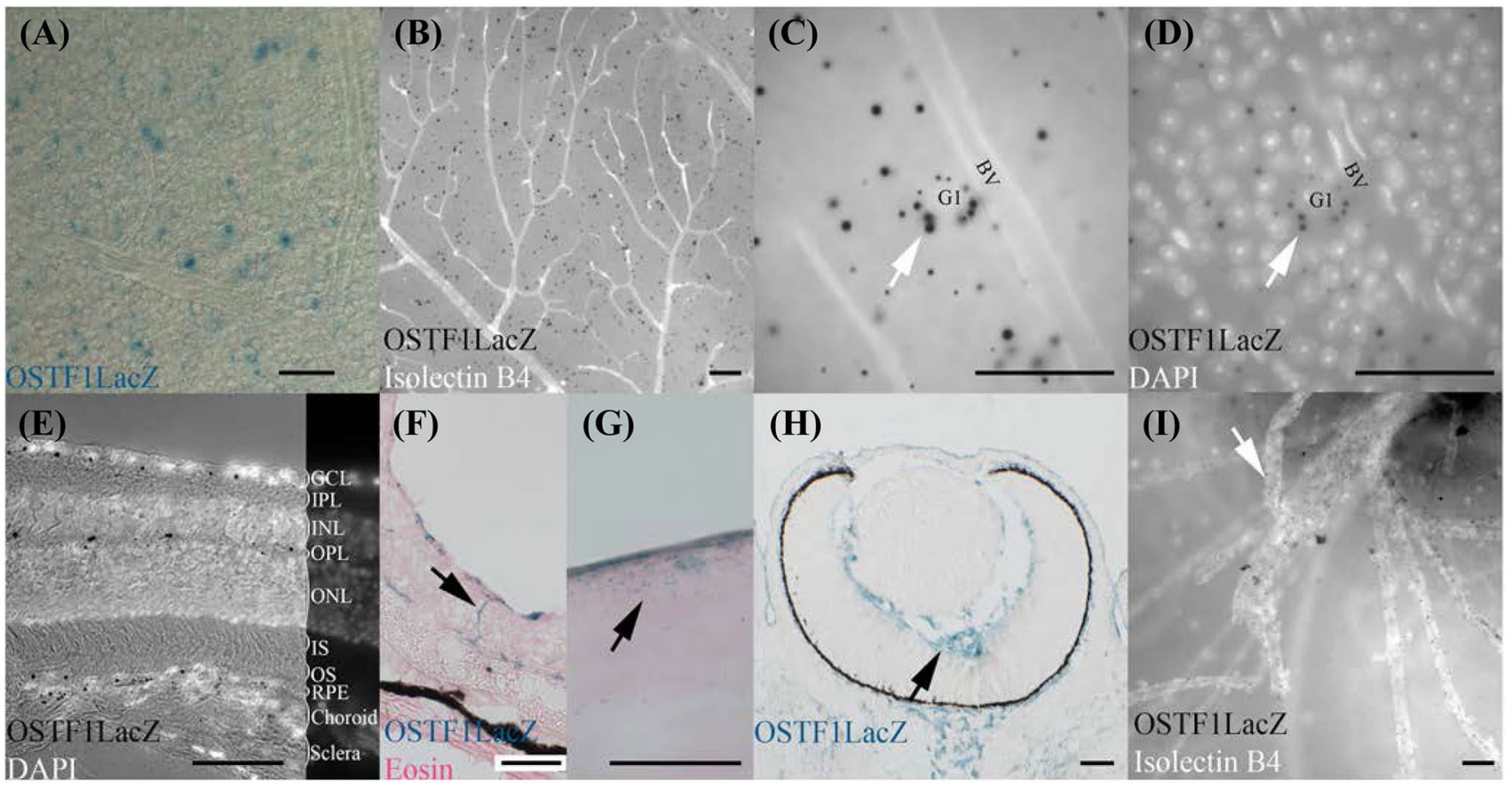

Fig. 4 OSTF1 is expressed in the eye. a-d LacZ stained flat mounted retina indicate OSTF1 is scattered on the retina surface. $\mathbf{b}$, c Isolectin-B4 staining (white in panel b, c) does not colocalise with OSTF1, suggesting that the retinal blood vessels (BV) do not express OSTF1. c, d OSTF1 is found concentrated, in the ganglia cell layer, around cells with large nuclei (stained with DAPI) and cytoplasm (arrow), presumably G1 cells. e In transverse section of the retina of an OSTF1 $1^{\text {LacZ/LacZ }}$ albino mouse, OSTF1 is found in the ganglia cell layer (GCL), the outer plexiform layer (OPL) and the retinal pigmented epithelium (RPE) but not the inner plexiform layer (IPL), inner nuclear layer (INL), outer nuclear layer (ONL), inner (IS) and outer segments (OS) of the photoreceptors, choroid and sclera. f Muller glial cells (arrow) express OSTF1. $g$ The outer cells of the cornea express OSTF1. h, i In the embryo and P6 pup, OSTF1 is found in the capillary network (arrows) and can be counterstained with isolectin B4 (white in panel i). All scale bars $=50 \mu \mathrm{m}$ 
SG) was weak, diffuse, and similar to that seen in the motor nerves at the Motor Exit Point (MEP, Fig. 3i), suggestive of a glial origin.

\section{Sensory organs-ear and eye}

In the ear, Ostfl was observed in the cochlear epithelium in the embryo (Fig. 2p, notched blue arrowhead) and also the adult (data not shown). Ostfl signal in the eye appears to be restricted to the retina. Striking differences in expression were observed between the developing and mature structures. In the developing eye and up until early postnatal stages when the retinal vasculature is completely remodelled (Pitulescu et al. 2010), Ostfl was exclusively found in the blood vessels (Fig. 4h, i). In contrast, in the adult retina, Ostfl was excluded from blood vessel networks lining the ganglia cell layer (Fig. 4a-d) and instead restricted to specific deeper layers (Fig. 4e, f) as well as outer layers of the
Fig. 5 OSTF1 is expressed in lung and liver tissues. a In adult lung, OSTF1 is expressed in the alveolar parenchyma (Alv), the epithelium of bronchus $(\mathrm{Br})$ and terminal bronchus ( $\mathrm{TBr}$ ) and blood vessel endothelium (Bv). b In embryonic lung (E15), OSTF1 is detected in the developing capillary network, but not in the bronchus (arrowhead). c In embryonic liver (E15), we find OSTF1 expression in distinct cells spread in the parenchyme, likely to be hematopoietic stem cells. d In contrast, in the adult liver, OSTF1 is found exclusively in endothelial cells in a low-to high gradient from the hepatic zone 1 surrounding the portal vein $(\mathrm{PV})$ to zone 3 around the central vein $(\mathrm{CV})$. Scale bars $=100 \mu \mathrm{m}$

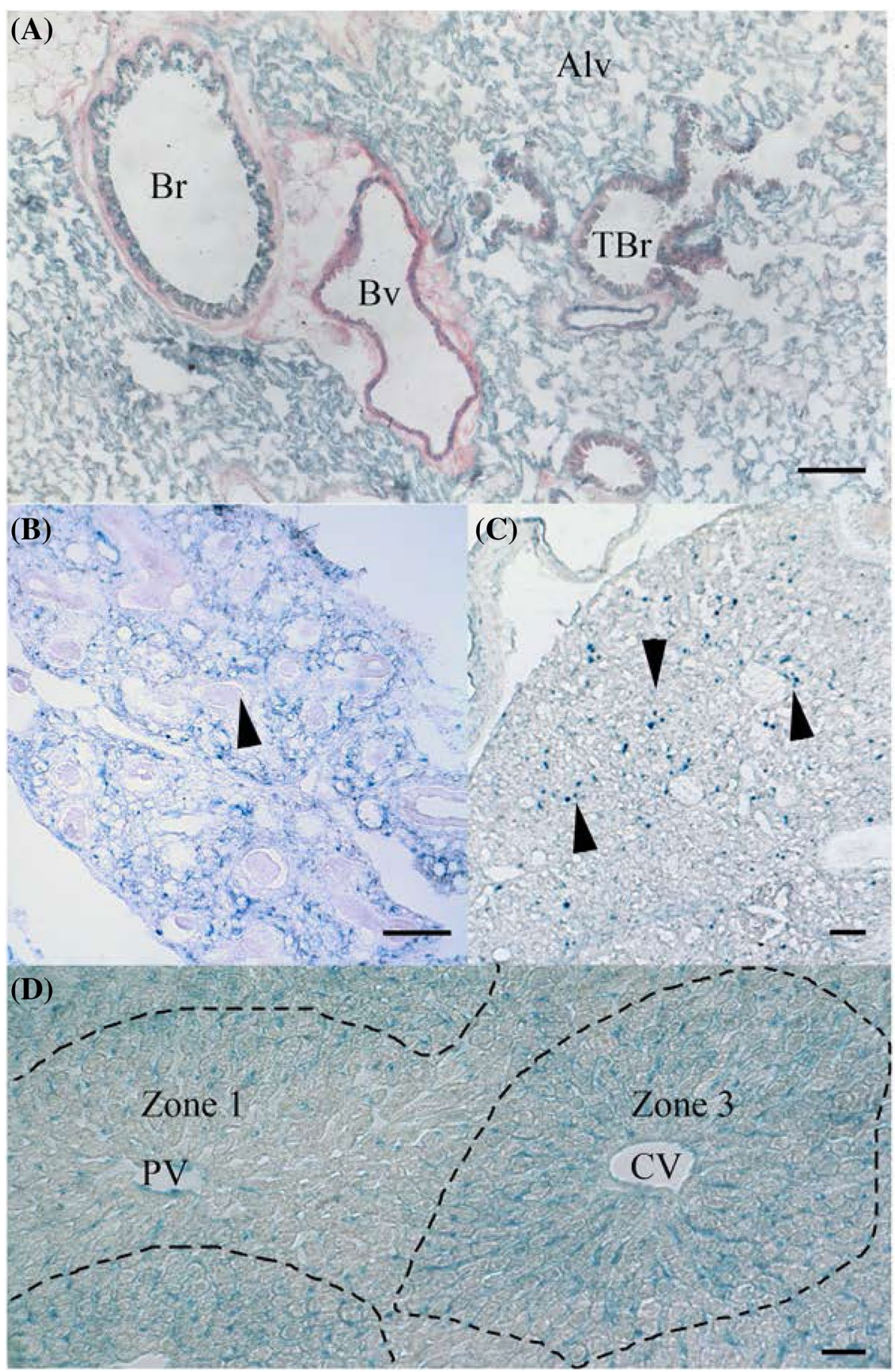


cornea (Fig. 4g). Flat mounting of the retina revealed Ostf1 expression on the eye's inner surface was present in the ganglia cell layer (GCL, Fig. 4a, b). However, some signal was clustered around a few cells (Fig. 4c, arrow). Judging by their larger nuclei and somata (Fig. 4d, arrow), these were possibly G1 cells (Volgyi et al. 2009). In transverse section (Fig. 4e, f), LacZ was detected in GCL, in the outer plexiform layer (OPL), where horizontal cells reside, and in the retinal pigmented epithelium (RPE). In a few sections, we observed large columnar LacZ positive Muller glial cells connecting the GCL with the border between outer nuclear layer (ONL) and photoreceptor inner segment (IS) (Fig. 4f, arrow).

\section{Lung}

X-Gal staining shows Ostf 1 expression in the embryonic lung at E14 and in the adult tissue. In adult lung, Ostf1 appears ubiquitous in the respiratory epithelium of the alveolar parenchyme (Fig. 5a, Alv). It is also found in the epithelium of the bronchi $(\mathrm{Br})$ and of the terminal bronchi (TBrl). As in most tissues, OSTF1 is found in the endothelial cells of blood vessels (Bv), according to vessel morphology both arterioles and venules. In contrast, in the embryo, Ostfl localises to the growing network of blood vessels but is excluded from the bronchi (Fig. 5b, arrow).

\section{Liver}

Expression of Ostfl changes dramatically between embryonic and adult liver (Fig. 5c, d). In the embryo, Ostf1 is strongly expressed in cells scattered around the liver (Fig. 5c, arrows), which may represent hematopoietic stem cells, but it is absent from the remainder of the organ. In contrast, in adult liver, Ostfl is absent from the hepatocyte cordons, but strongly expressed in the sinusoidal endothelial cells that surround the central veins (Fig. 5d, dashed lines, $\mathrm{Cv}$ ). Interestingly, compared to the area surrounding the central vein, Ostf 1 expression surrounding the portal vein is weaker and limited to a subset of endothelial cells (Fig. 5d, $\mathrm{PV})$. This is suggestive of a gradient from low-to-high Ostf1 expression from hepatic acinus zone $1-3$, which is accompanying blood flow.

\section{Heart}

In the adult heart, Ostfl was found to be expressed in the endothelium of the atrium (Fig. 6a, red arrowhead in At) and the vasa vasorum of the ventricle (Fig. $6 \mathrm{a}, \mathrm{Vv}$, black arrowheads and Vent) but surprisingly it was not found lining the inside of the ventricles (data not shown). Some heart myocytes and pericardial cells expressed low levels of Ostf1 as seen by small X-Gal puncta (Fig. 6a). In embryonic heart

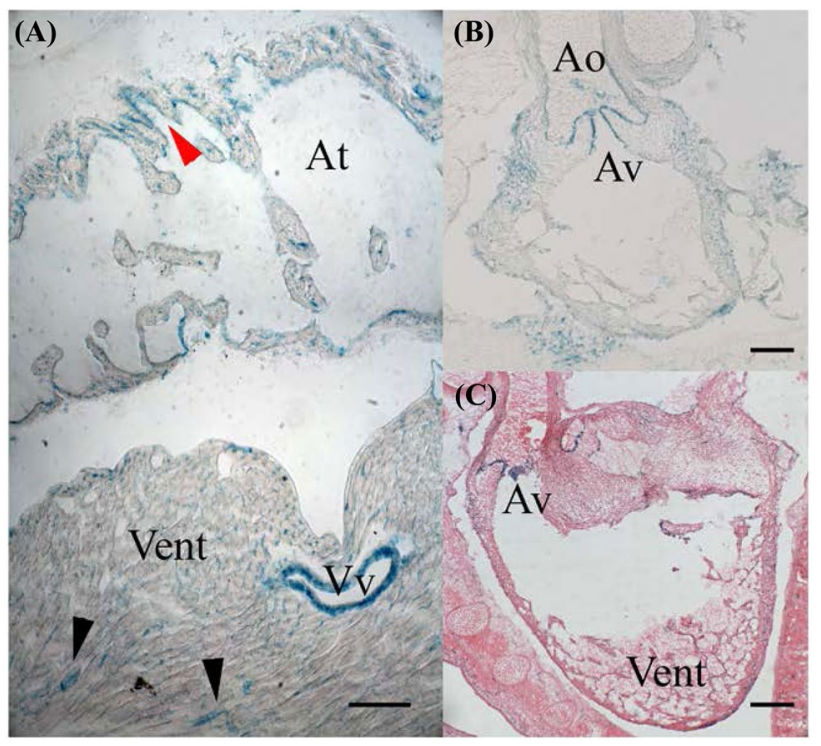

Fig. 6 OSTF1 is expressed in the adult and embryonic heart. a In the adult heart, OSTF1 is found in the endothelium (red arrow) of the atrium (At), the large ( $\mathrm{Vv})$ and small vessels (arrowheads) that form the vasa vasorum of the ventricle (Vent). Small puncta indicate that the cardiomyocytes also express OSTF1. b, c In embryos, OSTF1 expression is seen in the aortic valves (Av) and the endothelium of the aorta (Ao) but not in the cardiac endothelium itself. Scale bars $=$ $100 \mu \mathrm{m}$

at E14, Ostf1 was found to be expressed at the surface of the lips of the aortic valve (Fig. 6b, c, Av), as well as the endothelium of the aorta (Fig. 6b, Ao).

\section{Kidney}

Ostfl was widely expressed in the kidney, from cortex to ureter (Fig. 7a). In the cortex, Ostfl was found in the glomeruli (Fig. 7b, Gl) and associated blood vessels and the proximal convoluted tubule. In the medulla (Fig. 7c), Ostfl was found to be expressed to varying degrees in all tubules, with highest expression in the proximal convoluted tubules. In both regions, blood vessels were LacZ positive (Fig. 7d) both in the endothelium and also in the underlying smooth muscle rings. The renal papilla clearly exhibited the highest level of Ostflexpression in the kidney (Fig. 7a, e). Kidney OstfI expression clearly begins early with LacZ being detected throughout the kidney at P0 except for the outer nephrogenic zone (Fig. 7f) and in blood vessels of the developing organ at E14 (Fig. $7 \mathrm{~g}$ ). Ostf1 expression was markedly absent from the adrenal glands at this timepoint (Fig. 7f, asterisks). 
Fig. 7 OSTF1 is highly expressed in the kidney. a Transverse section through adult kidney demonstrates that OSTF1 is expressed in the cortex (Ctx), Medulla (Med), blood vessels $(\mathrm{Bv})$, calyx $(\mathrm{Cx})$ and Ureter but not in the underlying adipose tissue. $\mathbf{b}$ In the cortical region, OSTF1 is found in the glomeruli (Gl) and the proximal convoluted tubules. c OSTF1 is expressed at varying levels in all tubules of the medulla. $\mathbf{d}$ Renal arteries express OSTF1 in the endothelium and underlying smooth muscle. e The ureter wall expresses OSTF1 in a mosaic of high expression patches surrounded by low expression. f Whole mount expression in the P0 kidney shows wide expression in the kidneys and ureter (arrowhead) but not the adrenal glands $(*)$. g In the embryonic kidney, OSTF1 is exclusively confined to the developing capillary network. Scale bars $=100 \mu \mathrm{m}$
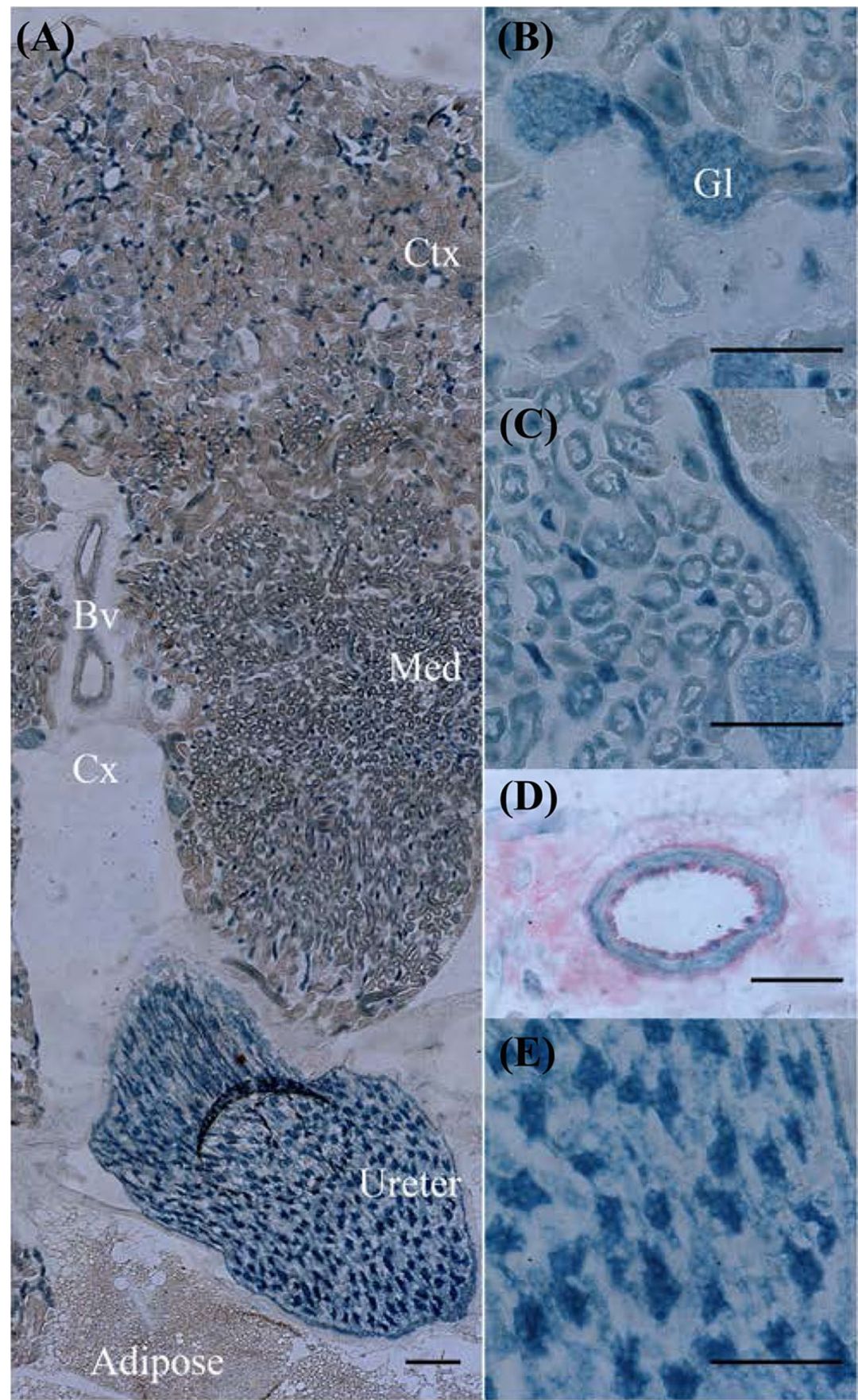

(F)
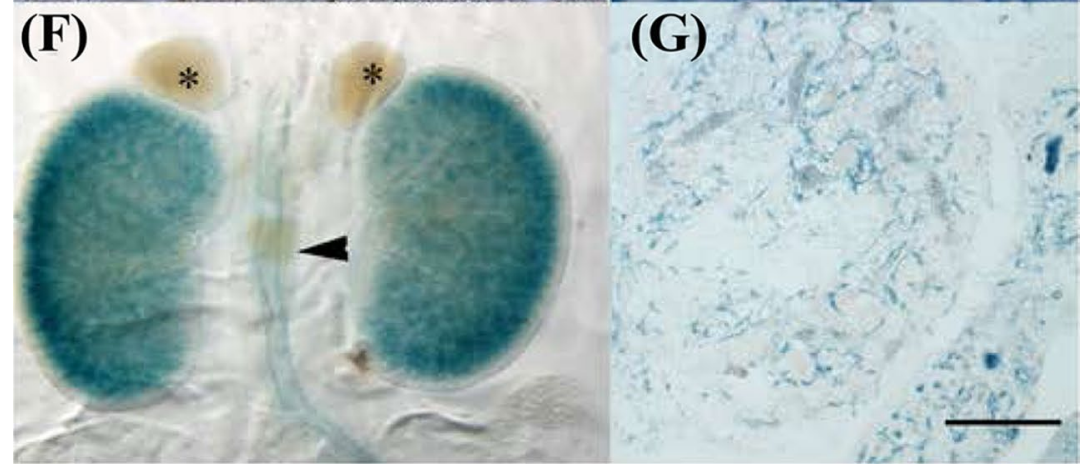


\section{Placenta}

All the embryo-derived parts of the E14 placenta were found to be LacZ positive (Fig. 8a, b); this applied particularly to the labyrinth and spongiotrophoblast (Fig. 8b, Lab and $\mathrm{Sp}$ ). This may in part be due to the large amount of vasculature in that region. In the umbilical cord, the highest level of expression was observed in the endothelial lining of the blood vessels (Fig. 9c, Bv), but no expression was found in the underlying gut structure (Fig. 9c, gut).

\section{Expression in bone tissue}

Given that OSTF1 is thought to impact osteoclast activity (Reddy et al. 1998), its identification in bones was seen as a priority. In embryonic tissue, the pre-existing cartilage matrix that will develop into bone was only LacZ positive
(A)
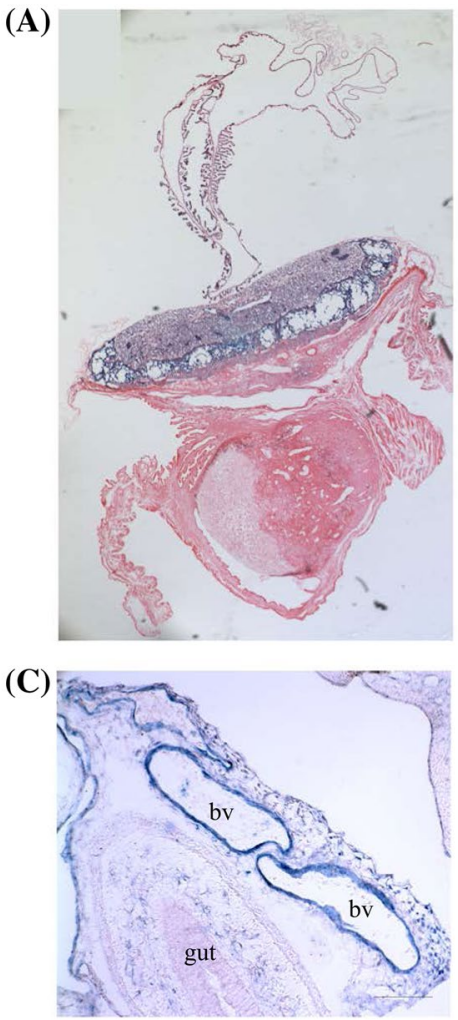

(B)

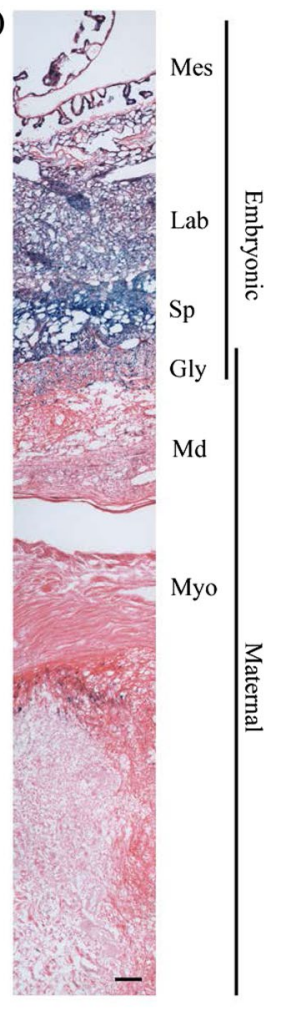

Fig. 8 OSTF1 is expressed throughout the embryonic placenta and the umbilical cord. a Low magnification view of the placenta of an Ostf $1^{\text {LacZ/LacZ }}$ embryo implanted in the uterine wall of its $O s t f 1^{+/ L a c Z}$ mother. b All tissues of embryonic origin express high levels of OSTF1, specially the spongiotrophoblast layer (Sp) and the labyrinth layer (Lab). The glycogen cells also express high levels of OSTF1 while less is found in the maternal decidua (Md) and none in the myometrium (Myo). There is high level of expression in the mesodermal cells of the yolk sac (Mes). $\mathbf{c}$ In the umbilical cord, there is high level of expression in the blood vessels (bv) but none in the gut. Scale bar $\mathbf{a}=500 \mu \mathrm{m}$, scale bars in $\mathbf{b}, \mathbf{c}=100 \mu \mathrm{m}$

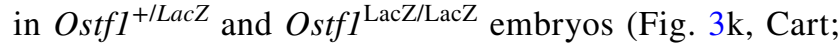
Fig. 2n, arrows pointing to lower jaw and facial bone primordium), but not their wild-type siblings, suggestive of OstfI expression in bone. More developed bone tissues harbour endogenous beta-galactosidase-like activity, in particular in osteoclasts (Kopp et al. 2007), making it problematic to draw conclusion from X-Gal staining of developing or indeed established bones. We, therefore, performed semi-quantitative RT-PCR of cultured osteoclast and osteoblasts as they differentiated from bone marrow to identify whether they expressed Ostf1. Ostfl expression was detected at all stages of differentiation of both cell types. However, while Ostf1 appeared to be evenly expressed in osteoclasts throughout differentiation, its expression in osteoblasts decreased over time (Fig. 10a, b).

\section{Phenotyping of the Ostf1 $1^{\mathrm{LacZ} / L a c Z}$ mouse}

We have generated a mouse that is knocked out for Ostf1. In absence of any clear developmental phenotype, and in order to define where, when and what could be perturbed by loss of Ostfl expression, we have characterised the expression of Ostf1 in embryonic and adult mouse. In parallel to the LacZ staining, we have analysed the histology of the various tissues analysed by routine haematoxylin and eosin staining and observed no significant histological abnormalities. It is, however, possible that the physical or functional abnormalities may not show up by simple histology.

\section{Bone phenotyping}

OSTF1 was first described as an indirect osteoclast stimulating factor. We, therefore, compared the differentiation of Ostf1 $1^{\text {LacZ/LacZ }}$ osteoclasts with wild-type controls. Following differentiation in vitro, primary bone marrow-derived osteoclasts were stained for Tartrate Resistant Acid Phosphatase (TRAP) to permit quantitation of osteoclast differentiation. No difference was observed in the ability of primary bone marrow-derived macrophages to differentiate into TRAP-positive osteoclasts between wild-type (400.5/ Well, SEM 32.1, Fig. 9c) and Ostf1 ${ }^{\text {LacZ/LacZ }}$ (447/well, SEM $15.7, p=0.21)$ cultures. Thus, OSTF1 is not required for osteoclast differentiation in vitro.

We next investigated whether loss of Ostfl might impact on osteoclast activity, and analysed bone density by microCT scanning, focussing on tibiae and femurs of age-matched knockout and wild-type male mice (15 weeks; $n=8 \mathrm{WT}$, $6 \mathrm{KOs}$, both legs scanned). This method, which relies on $\mathrm{X}$-ray imaging of a rotating bone, reveals the fine trabecular bridges located under the growth plate without destroying the bone. Images were reconstructed and a volume of interest located just under the growth plate was computationally analysed for bone volume, density and surface (Fig. 9d). 
(A)

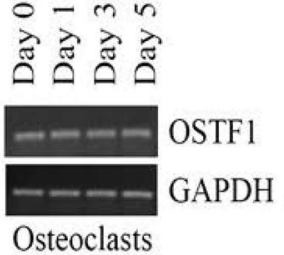

(D)

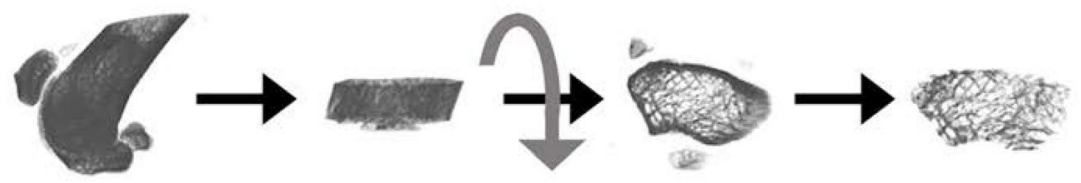

(E)

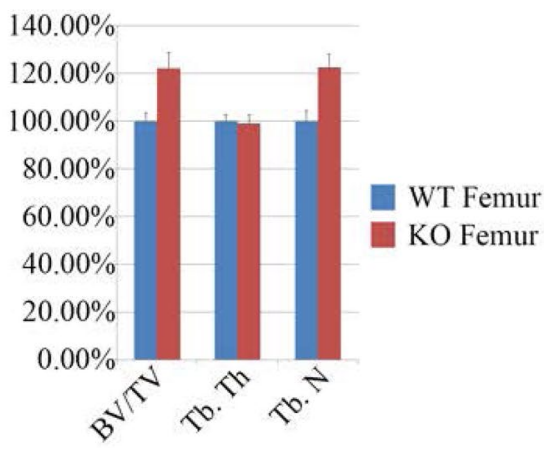

Fig. 9 RT PCRs indicate OSTF1 is expressed in osteoclasts and osteoblasts and its loss leads to increased bone density. a Ostf1 mRNA is detected in differentiating osteoclast cells from primary bone marrow-derived macrophages at day 0 until fully differentiated at day 5. GAPDH was used as a positive control. b Ostf1 mRNA is also expressed throughout osteoblasts differentiation. TBP was used as a positive control. c Loss of Ostf1 expression does not perturb osteoclast differentiation. Equal numbers of primary bone marrow-derived macrophages from wild type and (WT) Ostf1 $1^{\text {LacZ/LacZ }}(\mathrm{KO})$ male mice were plated and differentiated to osteoclast in vitro ( $n=3$ for each genotype). Mature osteoclasts were identified and quantified following TRAP staining (n.s. not significant). d Micro-CT scanning pro-

This revealed that $O s t f 1^{\mathrm{LacZ} / \mathrm{LacZ}}$ tibia and femur were significantly denser than wild-type counterparts. Normalised to wild type, the ostfl $^{\text {LacZ/LacZ }}$ bone volume/tissue volume (BV/TV) was $122 \%$ (SEM 6.5\%, $p<0.01$ ) for the femur and $118.43 \%$ (SEM $2.33 \%, p<0.01$ ) for the tibia. Whilst trabecular thickness of WT and Ostf1 ${ }^{\text {LacZ/LacZ }}$ bones was indistinguishable, the trabecular number was increased in Ostf $1^{\mathrm{LacZ} /}$ LacZ to $122.52 \%$ (SEM $5.49 \%, p<0.01$ ) in the femur and to $115.41 \%$ (SEM $2.31 \%, p<0.01$ ) in the tibia (Fig. 9e, $\mathrm{f}$ and Supplemental Fig. 2). We concluded that loss of OSTF1 confers mild osteopetrosis-like phenotype caused by an increase in trabecular number but not thickness.
(F)

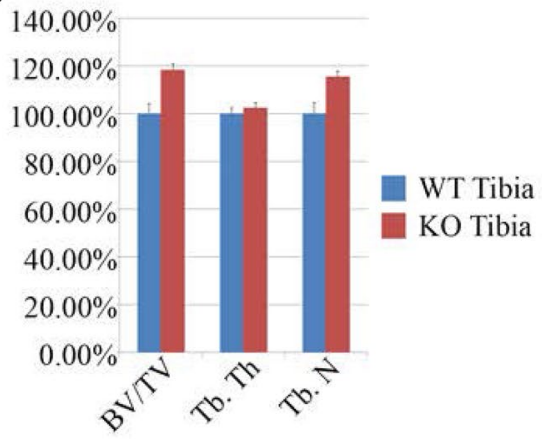

cedure from bone scanning to selection of trabecular bone for analysis. e Femurs from adult male Ostf1 $1^{\text {LacZ/LacZ }}$ mice $(n=14)$ exhibit elevated bone density (BV/TV $p \leq 0.01$, asterisk) and trabecular number (Tb.N $p \leq 0.01$, asterisk) compared to wild type (WT-n=16) as ascertained by $\mu \mathrm{CT}$ scanning. No difference in trabecular thickness (Tb.Th $p>0.2$, n.s. not significant) was observed. f Tibia from adult male Ostf1 ${ }^{\text {LacZILacZ }}$ mice $(n=12)$ exhibit elevated bone density (BV/ $\mathrm{TV} p<0.01$, asterisk) and trabecular number (Tb.N $p<0.01$, asterisk) compared to wild type (WT $-n=16$ ) as ascertained by $\mu \mathrm{CT}$ scanning. No difference in trabecular thickness (Tb.Th $p>0.2$, n.s. not significant) was observed

\section{OSTF1 interacting proteins}

In order to understand how OSTF1 might influence bone density, a proteomic approach was used to identify OSTF1interacting proteins in HEK293 cells, the cell line which was first used to demonstrate that OSTF1 stimulated secretion of a factor/s that promoted osteoclast differentiation (Reddy et al. 1998). HEK293 cells were transfected in triplicate with either empty vector (Vector) or a vector encoding human OSTF1 tagged at the N-terminus with a V5-epitope tag (V5-OSTF). Cell lysates were then subjected to V5 immunoprecipitation and co-immunoprecipitating proteins identified by LC-MS/MS. 
This approach identified 18 proteins that were significantly enriched $(p<0.05)$ in IPs from cells expressing V5-OSTF1 compared to vector control (Fig. 10a; Table 2). This list contained both cytosolic and nuclearlocalised proteins which were reflected by the subcellular

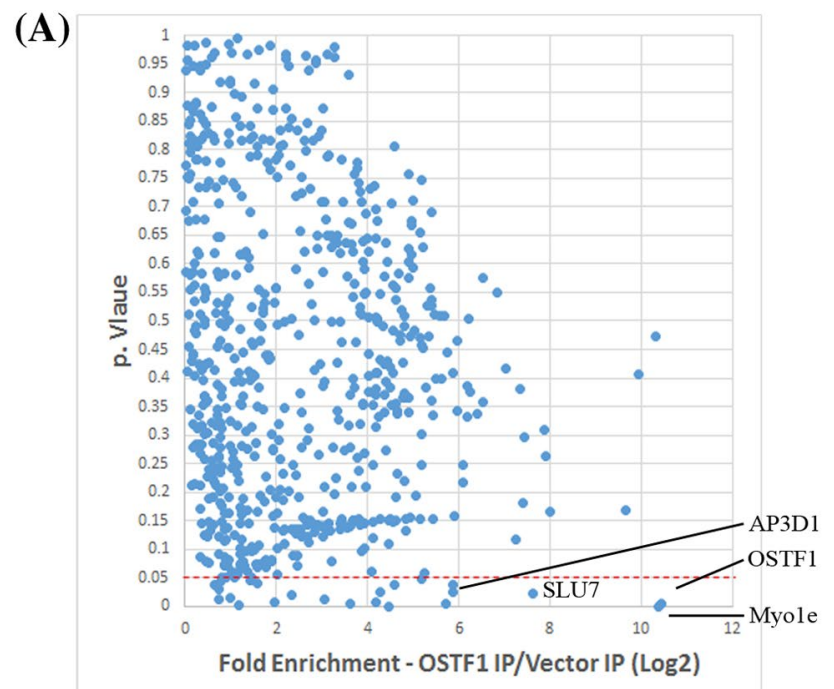

(B)
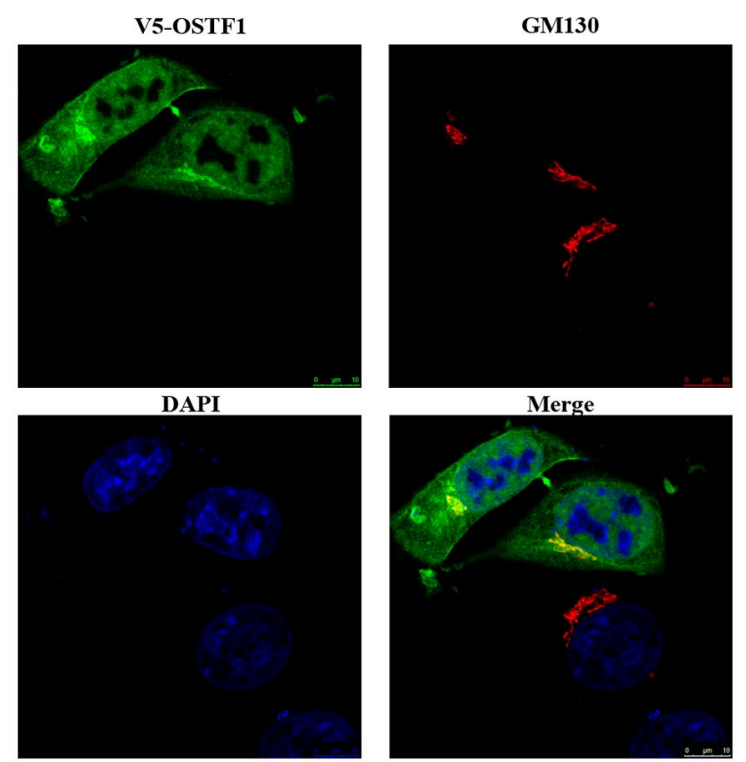

Fig. 10 Identification of OSTF1-interacting proteins. a Volcano plot showing proteins identified by LC-MS/MS that are enriched in V5-OSTF1 IPs. HEK293 cells were transiently transfected in triplicate with empty vector or V5-OSTF1. Lysates were subjected to V5 IP and co-immunoprecipitating proteins identified by LC-MS/MS. $\mathrm{X}$-axis shows average fold enrichment of individual proteins (blue points) in cells expressing V5-OSTF1 compared to empty vector. $\mathrm{Y}$ axis shows $p$ value. Dashed red line represents $p=0.05$ cutoff. b OSTF1 localises to the cytosol, nucleus and golgi. V5-OSTF1 was transiently transfected into HEK293 cells, and cells were fixed, permeabilised and immunostained with anti-V5 antibody (green), antiGM130 (red) to stain the golgi, and DAPI (blue) to label the nucleus. Scale bar $=10 \mu \mathrm{m}$ localisation of V5-OSTF1 in transfected HEK293 cells. Immunofluorescence demonstrated V5-OSTF1 to be localised to the cytosol, the golgi and the nucleus, but excluded from regions of dense chromatin (Fig. 10b). Reassuringly, the top interacting protein was Myosin $1 \mathrm{e}$, which has been previously identified to interact with OSTF1, and is thought to regulate cytoskeletal reorganisation and vesicular trafficking (Tanimura et al. 2016). Interestingly, Myosin 1e has also been demonstrated to regulate secretion of the chemokine CCL2, deficiency of which causes increased bone mass in mice (Sul et al. 2012; Wenzel et al. 2015). An additional OSTF1-interacting protein was found to be AP3D1, a subunit of the golgi-localised AP3 vesicular trafficking complex, disruption of which leads to dysregulation of peptide hormone release in mice (Sirkis et al. 2013). The majority of the remaining interacting proteins are associated with nuclear functions including RNA splicing, chromatin remodelling and gene expression (Table 2). A notable absence was SMN1, although this may reflect the cell type used in the immunoprecipitation experiment. However, many of the OSTF1-interacting proteins identified function in RNA splicing, where SMN1 facilitates the assembly of snRNP spliceosome components.

\section{Behaviour phenotyping}

Although we did not identify SMN as an OSTF-interacting protein in HEK293 cells, this interaction may still occur in other cell types such as motor neurons. OSTF1 was previously reported to interact with SMN (Kurihara et al. 2001), loss of SMN impacts bone development (Shanmugarajan et al. 2007) and SMN is expressed by osteoclasts (Kurihara et al. 2001), we wondered if the Ostf ${ }^{\text {LacZ/LacZ }}$ would share phenotypes seen in SMN mutant mice. SMN knockout mice are embryonic lethal (Schrank et al. 1997) and hypomorphs suffer from muscle weakness that inversely correlates with the level of SMN expression (Edens et al. 2015; Lefebvre et al. 1997). This is clearly not the case of the Ostfl mice which live up to a year without obvious phenotype but it was still possible that Ostf1 mice behave abnormally.

As many of the OSTF1-interacting proteins (Table 2) result in neurological defects and human microdeletion patients where the OSTF1 gene is one of six deleted genes also display neurological abnormalities, Ostfl mice were rigorously examined via a SHIRPA protocol, a battery of non-intrusive tests where mice are observed mostly unchallenged (Rogers et al. 1997). These tests are designed to monitor neuropsychiatric, cerebellar and sensory functions

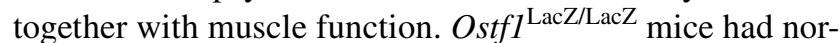
mal SHIRPA score (Fig. 11a). Part of the SHIRPA protocol involves balance and coordination tests where mice are put on a grid, the grid is suddenly inverted and lightly shaken 
Table 2 Table showing the identity, function, disease association, fold enrichment and $p$ value of proteins identified as co-immunoprecipitating with V5-OSTF1 from HEK293 cells

\begin{tabular}{|c|c|c|c|c|c|c|}
\hline Gene symbol & Full name & Function & Disease associations & $\begin{array}{l}\text { Log2 fold } \\
\text { enrich- } \\
\text { ment }\end{array}$ & $\begin{array}{l}\text { Actual fold } \\
\text { enrichment }\end{array}$ & $p$ Value \\
\hline OSTF1 & $\begin{array}{l}\text { Osteoclast stimulation } \\
\text { factor } 1\end{array}$ & Cytoskeleton & $\begin{array}{l}\text { Deleted in microdeletion } \\
\text { sydrome with epilepsy } \\
\text { and intellectual disability }\end{array}$ & 10.4 & 1391.1 & 0.003478529 \\
\hline MYO1E & Myosin 1E & $\begin{array}{l}\text { Vesicular trafficking; actin } \\
\text { reorganisation }\end{array}$ & $\begin{array}{l}\text { Mutated in focal segmental } \\
\text { glomerulosclerosis-6 }\end{array}$ & 10.4 & 1319.5 & 0.000231218 \\
\hline SLU7 & SLU7 homolog & RNA splicing & & 7.6 & 196.2 & 0.023058311 \\
\hline AP3D1 & $\begin{array}{l}\text { Adaptor-related protein } \\
\text { complex 3, delta-1 subuint }\end{array}$ & Vesicular trafficking & $\begin{array}{l}\text { Mutated in Hermansky- } \\
\text { Pudlak syndrome and } \\
\text { "mocha" mose model }\end{array}$ & 5.9 & 58.1 & 0.024118142 \\
\hline ACIN1 & $\begin{array}{l}\text { Apoptotic chromatin con- } \\
\text { densation inducer } 1\end{array}$ & $\begin{array}{l}\text { Apoptotic chromatin con- } \\
\text { densation; RNA splicing }\end{array}$ & & 5.9 & 58.1 & 0.038838599 \\
\hline GTPBP4 & GTP-binding protein 4 & Unknown & & 5.7 & 52.6 & 0.005445883 \\
\hline TOP2B & $\begin{array}{l}\text { Topoisomerase (DNA) II } \\
\text { beta }\end{array}$ & $\begin{array}{l}\text { Transcription; DNA } \\
\text { replication; chromatin } \\
\text { remodelling }\end{array}$ & & 5.2 & 36.5 & 0.047338493 \\
\hline DNTTIP2 & $\begin{array}{l}\text { Deoxynucleotidyltrans- } \\
\text { ferase terminal interacting } \\
\text { protein } 2\end{array}$ & $\begin{array}{l}\text { Transcription; chromatin } \\
\text { remodelling }\end{array}$ & & 4.6 & 23.9 & 0.037307658 \\
\hline SCAF11 & $\begin{array}{l}\text { SR-related CTD associated } \\
\text { factor } 11\end{array}$ & RNA splicing & & 4.5 & 22.2 & 0.000497072 \\
\hline SNIP1 & $\begin{array}{l}\text { Smad nuclear interacting } \\
\text { protein } 1\end{array}$ & Transcription & $\begin{array}{l}\text { Mutations cause PMRED } \\
\text { (psychomotor retardation, } \\
\text { epilepsy, and craniofacial } \\
\text { dysmorphism) }\end{array}$ & 4.3 & 19.4 & 0.024277978 \\
\hline UPF3B & $\begin{array}{l}\text { UPF3B, regulator of non- } \\
\text { sense mediated mRNA } \\
\text { decay }\end{array}$ & $\begin{array}{l}\text { mRNA surveillance; non- } \\
\text { sense mediated decay }\end{array}$ & $\begin{array}{l}\text { Mutations in XLID } \\
\text { (X-linked intellectual } \\
\text { disability) with autism, } \\
\text { ADHD and scizophrenia }\end{array}$ & 4.2 & 18.0 & 0.007231004 \\
\hline FAM98B & $\begin{array}{l}\text { Family with sequence simi- } \\
\text { larity } 98 \text { member B }\end{array}$ & RNA transport & & 3.6 & 12.3 & 0.00373743 \\
\hline PAK1IP1 & PAK1 interacting protein 1 & Ribosomal stress response & $\begin{array}{l}\text { Mutated in mouse model of } \\
\text { orofacial clefting }\end{array}$ & 3.0 & 8.2 & 0.011385542 \\
\hline SS18 & $\begin{array}{l}\text { SS18, nBAF chromatin } \\
\text { remodelling complex } \\
\text { subunit }\end{array}$ & Transcription & $\begin{array}{l}\text { Chromosomal translocation } \\
\text { causes synovial sarcoma }\end{array}$ & 2.3 & 5.1 & 0.019649035 \\
\hline YTHDC1 & YTH domain containing 1 & RNA splicing & & 2.0 & 3.9 & 0.006920967 \\
\hline RNPS1 & $\begin{array}{l}\text { RNA binding protein with } \\
\text { serine rich domain } 1\end{array}$ & $\begin{array}{l}\text { RNA transport; nonsense } \\
\text { mediated decay }\end{array}$ & & 1.6 & 3.0 & 0.040180758 \\
\hline FTSJ3 & FTSJ3 & rRNA processing & & 1.4 & 2.7 & 0.04653522 \\
\hline FIP1L1 & $\begin{array}{l}\text { Factor interacting with } \\
\text { PAPOLA and CPSF1 }\end{array}$ & RNA polyadenylation & $\begin{array}{l}\text { Interstitial chromosomal } \\
\text { deletion results in fusion } \\
\text { to the PDGFRA gene } \\
\text { in chronic eosinophilic } \\
\text { leukaemia }\end{array}$ & 1.2 & 2.3 & 0.002115712 \\
\hline
\end{tabular}

and time taken for mice to release their grip recorded. The Ostf $1^{\text {LacZ/LacZ }}$ cohort showed no difference than control siblings (Fig. 11b). Next, gait of wild type and mutant mice were examined using a cat walk box, a transparent box with a translucent bottom where paw position can be observed (Fig. 11c). Mice were filmed running for one metre towards the relative shade of an empty cardboard tube. Movies were analysed by recording paw print using a custom imageJ plugin. Each paw strike gave a coordinate that could then be plotted (Fig. 11d) and from which step size was calculated. Thus, plotting against frame allows analysis of paw strike synchrony (Fig. 11e), and plotting against step allows to see if the run is regular (Fig. 11f). Finally, by averaging the step for each paw for each animal, it was possible to see if there 
was a difference in step size between wild type, Ostf $1^{\text {LacZ/+ }}$ and $O s t f I^{\text {LacZ/LacZ }}$. Analysis of the movies did not reveal any difference between cohorts: all animals had regular synchronic gait and normal step size, (Fig. 11g).

Ostf1 is expressed in the hippocampus and the mammillary bodies, which are thought to be involved in olfactory memory (Yokosuka et al. 1999). We tested our mice for olfaction defects by habituating them to chocolate then introduced them to a clean cage where chocolate was hidden under bedding (Yang and Crawley 2009). Mice were timed to find the chocolate up to a maximum of $10 \mathrm{~min}$. No difference between cohorts was observed in these tests (Fig. 11h).

Since there is significant expression of Ostfl in the inner ear epithelium and in the cochlear ganglion (Fig. 2p) mice were examined for signs of auditory defects by testing with a click box. Briefly, a small box produces a loud click and causes a flick of the ears [Preyer's reflex (Jero et al. 2001)] and a startle response characterised by neck contraction. Similar to the olfaction tests, no difference was observed in the auditory response between cohorts (Fig. 11i).

\section{Discussion}

OSTF1 was previously described as a cytoplasmic protein with $\mathrm{SH} 3$ and ankyrin domains that indirectly activates osteoclast differentiation and regulates their bone-resorbing activity (Reddy et al. 1998). OSTF1 was suggested to bind to a number of other proteins and previous studies suggested functions in spinal motor neuron atrophy and a microdeletion syndrome (9q21.13) (Baglietto et al. 2014; BoudryLabis et al. 2013; Kurihara et al. 2001; Lu et al. 2006; Szymkiewicz et al. 2004; Vinayagam et al. 2011). To our knowledge, we have generated the first Ostf1 mouse model. We show that this is a functional Ostfl knockout, with LacZ placed under control of Ostfl's regulatory elements. The
(A)

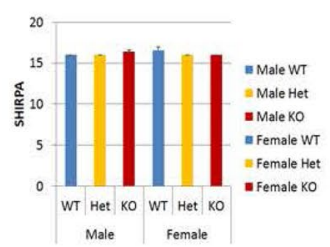

(D)

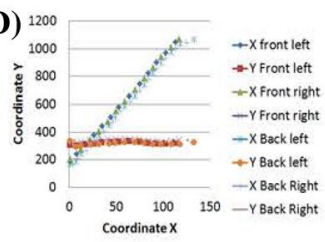

(G) 80

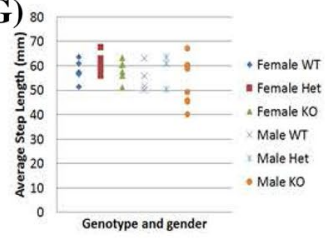

(B)

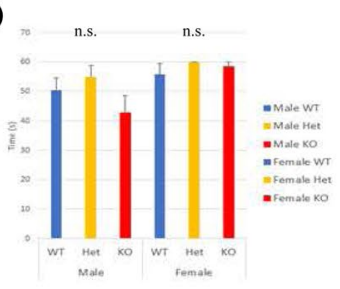

(C)

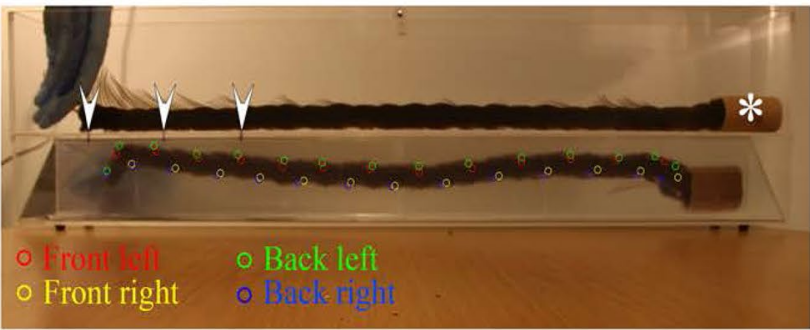

(E)

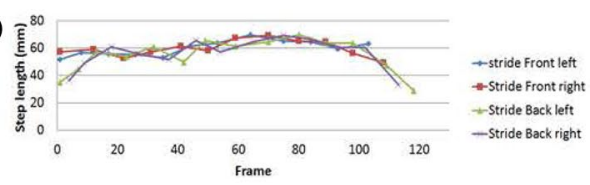

(F) $\bar{\varepsilon}$

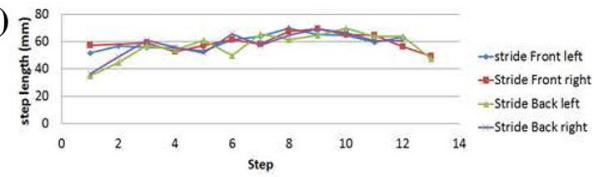

(H) 6

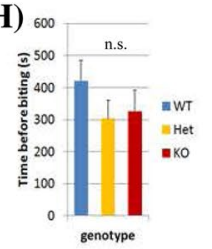

(I) 1

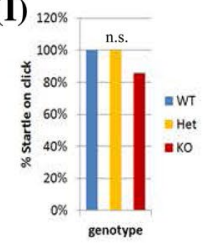

Fig. 11 Ostf $1^{\text {LacZ/LacZ }}$ mice behave normally. a No difference is observed between wild type, Ostf1 $1^{+/ L a c Z}$ and Ostf1 $1^{\text {LacZ/LacZ }}$ mice is SHIRPA test. b No difference is observed between wild type, Ostf $1^{+/ L a c Z}$ and Ostf1 $1^{\text {LacZ/LacZ }}$ mice in hang wire latency (WT male $n=4$, Het male $n=4$, KO male $n=8$, WT female $n=7$, Het female $n=7$, KO female $n=6$ ). c-f Gait analysis indicate that Ostf1 $1^{\text {LacZ/LacZ }}$ walk normally. $\mathbf{c}$ Representative flattened timelapse of a mouse walking through the cat walk box from being placed in the box (left, where the gloved hand is) to the relatively darker side where a cardboard tube is (asterisk). Each paw step is labelled with a coloured circle (front left, red; front right, yellow; back left, green; back right, blue). The three bars, pointed by white arrowheads, are at 10, 20 and $30 \mathrm{~cm}$ each from the side of the box and are used for step calibration. d Tracking of each paw as the mouse walks provides a set of coordinates showing that the mouse has walked without pause in a straight line. e From these coordinates, step length can be inferred and plotted against frame, showing coordination of front left and back right paws and front right and back left. f Likewise, step length plotted against step indicates that each paw moves regularly. $\mathbf{g}$ Average step size in millimetre for each animal tested indicate that there is no significant difference between genotype. h Mice show no difference in chocolate burrowing test indicating normal olfaction (n.s. not significant). i Mice show no difference in Preyer's auditory reflex (WT $n=11$, Het $n=11$, KO $n=14$, WT vs. Het $p>0.14$, WT vs. KO $p>0.25$, $n$.s. not significant) 
Ostf $1^{\text {LacZ/LacZ }}$ mice were fertile and without overt deleterious phenotype, at least in the absence of challenge. Significantly, none of the phenotypes observed in patients with the OSTF 1 -encompasing microdeletion syndrome were observed in either Ostf $1^{\text {LacZ/+ }}$ or Ostf $1^{\text {LacZ/LacZ mice, sug- }}$ gesting that heterozygous loss of OSTF1 is not causal of the pathogenesis of the syndrome in mice. However, it is possible that heterozygous loss of OSTF1 may modify the phenotype of loss of other genes within the 9q21.13 locus.

As expected, Ostfl was found to be expressed in osteoclasts. However, while loss of Ostf1 does not impair osteoclast differentiation, it has a mild effect on bone architecture since both tibia and femur of $O s t f 1^{\text {LacZ/LacZ }}$ have a higher BV/ $\mathrm{TV}$ than normal due to increase in trabecular number, but not thickness. Elucidating whether this is an effect on decreased osteoclastic activity or increased osteoblastic activity-or possibly both- will need to be further investigated. Since we and others have shown that OSTF1 interacts with Myosin 1e (which can regulate secretion of CCL2/MIP1) and AP3D1 (which regulates peptide hormone release) it will be interesting to investigate circulating hormones in Ostfl knockout mice.

OSTF1 has been reported to interact with SMN (Kurihara et al. 2001), a spinal muscular atrophy gene. Like SMN, OSTF1 is expressed in osteoclasts and motor neurons. However, we do not find embryonic lethality or rapid wastage associated with loss or downregulation of SMN (Lefebvre et al. 1997) in the Ostfl knockouts. Indeed, Ost$f 1^{\text {lacZ/LacZ }}$ behaves normally and live up to 1 year without showing signs of muscle wastage. It is, therefore, unclear if the OSTF1-SMN interaction originally found by yeast two hybrid and pull down of cell lysate (Kurihara et al. 2001) occurs in vivo.

Taking advantage of the LacZ cassette, we undertook an in-depth analysis of $O s t f 1$ expression in both embryonic and adult mice. While various electronic resources are available that provide expression analysis, they often lack detailed description and are generally limited to tissue level. We show here that Ostfl is expressed widely in multiple organs, tissues and cell types, including the brain where Ostfl expression was somewhat controversial (Baglietto et al. 2014; Boudry-Labis et al. 2013). Interestingly, our results indicate Ostfl is widely expressed in the vascular compartment (endothelial cells). However, Ostfl 1 is not found in all blood vessels, and throughout development, suggestive of a specialised function in a subset of vessels. Perhaps the most striking vascular expression of Ostfl was observed in the specialised vasculature of the liver. It will be interesting to test the functional relevance of this in the future, for instance by analysing angiogenesis and/or regeneration following liver damage. More complex still but not less striking is Ostf1 expression in the kidney, where it was found to be distributed to a series of specialised structure including the vasculature, the glomeruli and the nephrons. Given that unchallenged $O s t f I^{\text {LacZ/LacZ }}$ mice do not show and physical or histological signs of kidney disease, it will be interesting to challenge this organ too, to elucidate the functional relevance of this fascinating distribution.

Acknowledgements This study was supported by College of Medicine and Veterinary Medicine, University of Edinburgh. We are grateful to Stuart Ralston, Rob van't Hof, and Lorraine Rose for assistance with CT scanning, interpretation of bone results and osteoclast culture. We thank Myriam Hemberger and Luke Boulter for their help identifying structures in the placenta and liver. Many thanks to Jimi Willis and Andrew Finch of the IGMM Mass-Spec facility. We thank Sonja Vermeren for proofreading the manuscript.

Author contributions The Ostf1 $1^{\text {LacZ/LacZ }}$ mice were made in $\mathrm{FH}$ lab. MV and TH wrote the paper. MV performed the LacZ staining, microscopy and analysis, CT scanning, behaviour tests and designed the cat walk box which was constructed on site by IGMM workshop. RM wrote the ImageJ pluggin used for the cat walk test. SW and OA provided assistance with bone phenotyping and analysis. TH performed the immunostaining, mass-spectrometry and established the Ostf1 $1^{\text {LacZ }}$ line and conceived and directed the work.

\section{Compliance with ethical standards}

Conflict of interest On behalf of all authors, the corresponding author states that there is no conflict of interest.

Open Access This article is distributed under the terms of the Creative Commons Attribution 4.0 International License (http://creativecommons.org/licenses/by/4.0/), which permits unrestricted use, distribution, and reproduction in any medium, provided you give appropriate credit to the original author(s) and the source, provide a link to the Creative Commons license, and indicate if changes were made.

\section{References}

Baglietto MG, Caridi G, Gimelli G, Mancardi M, Prato G, Ronchetto P, Cuoco C, Tassano E (2014) RORB gene and 9q21.13 microdeletion: report on a patient with epilepsy and mild intellectual disability. Eur J Med Genet 57:44-46

Baranzini SE, Wang J, Gibson RA, Galwey N, Naegelin Y, Barkhof F, Radue EW, Lindberg RL, Uitdehaag BM, Johnson MR, Angelakopoulou A, Hall L, Richardson JC, Prinjha RK, Gass A, Geurts JJ, Kragt J, Sombekke M, Vrenken H, Qualley P, Lincoln RR, Gomez R, Caillier SJ, George MF, Mousavi H, Guerrero R, Okuda DT, Cree BA, Green AJ, Waubant E, Goodin DS, Pelletier D, Matthews PM, Hauser SL, Kappos L, Polman CH, Oksenberg JR (2009) Genome-wide association analysis of susceptibility and clinical phenotype in multiple sclerosis. Hum Mol Genet 18:767-778

Boudry-Labis E, Demeer B, Le Caignec C, Isidor B, Mathieu-Dramard M, Plessis G, George AM, Taylor J, Aftimos S, Wiemer-Kruel A, Kohlhase J, Anneren G, Firth H, Simonic I, Vermeesch J, Thuresson AC, Copin H, Love DR, Andrieux J (2013) A novel microdeletion syndrome at $9 \mathrm{q} 21.13$ characterised by mental retardation, speech delay, epilepsy and characteristic facial features. Eur J Med Genet 56:163-170

Chalasani N, Guo X, Loomba R, Goodarzi MO, Haritunians T, Kwon S, Cui J, Taylor KD, Wilson L, Cummings OW, Chen YD, Rotter 
JI, Nonalcoholic Steatohepatitis Clinical Research Network (2010) Genome-wide association study identifies variants associated with histologic features of nonalcoholic fatty liver disease. Gastroenterology 139, 1567-1576

Edens BM, Ajroud-Driss S, Ma L, Ma YC (2015) Molecular mechanisms and animal models of spinal muscular atrophy. Biochim Biophys Acta 1852:685-692

Fox CS, Heard-Costa N, Cupples LA, Dupuis J, Vasan RS, Atwood LD (2007) Genome-wide association to body mass index and waist circumference: the framingham heart study $100 \mathrm{~K}$ project. BMC Med Genet 8(Suppl 1):S18

Furney SJ, Simmons A, Breen G, Pedroso I, Lunnon K, Proitsi P, Hodges A, Powell J, Wahlund LO, Kloszewska I, Mecocci P, Soininen H, Tsolaki M, Vellas B, Spenger C, Lathrop M, Shen L, Kim S, Saykin AJ, Weiner MW, Lovestone S, Alzheimer's Disease Neuroimaging Initiative, AddNeuroMed consortium (2011) Genome-wide association with MRI atrophy measures as a quantitative trait locus for Alzheimer's disease. Mol Psychiatry 16:1130-1138

Idris AI, van 't Hof RJ, Greig IR, Ridge SA, Baker D, Ross RA, Ralston SH (2005) Regulation of bone mass, bone loss and osteoclast activity by cannabinoid receptors. Nat Med 11:774-779

Jero J, Coling DE, Lalwani AK (2001) The use of Preyer's reflex in evaluation of hearing in mice. Acta Otolaryngol 121:585-589

Kopp HG, Hooper AT, Shmelkov SV, Rafii S (2007) Beta-galactosidase staining on bone marrow. The osteoclast pitfall. Histol Histopathol 22:971-976

Kurihara N, Menaa C, Maeda H, Haile DJ, Reddy SV (2001) Osteoclast-stimulating factor interacts with the spinal muscular atrophy gene product to stimulate osteoclast formation. J Biol Chem 276:41035-41039

Lefebvre S, Burlet P, Liu Q, Bertrandy S, Clermont O, Munnich A, Dreyfuss G, Melki J (1997) Correlation between severity and SMN protein level in spinal muscular atrophy. Nat Genet $16: 265-269$

Lu M, Zhang L, Sartippour MR, Norris AJ, Brooks MN (2006) EG-1 interacts with c-Src and activates its signaling pathway. Int J Oncol 29:1013-1018

Mackenzie MA, Jordan SA, Budd PS, Jackson IJ (1997) Activation of the receptor tyrosine kinase kit is required for the proliferation of melanoblasts in the mouse embryo. Dev Biol 192:99-107

Massenet S, Pellizzoni L, Paushkin S, Mattaj IW, Dreyfuss G (2002) The SMN complex is associated with snRNPs throughout their cytoplasmic assembly pathway. Mol Cell Biol 22:6533-6541

Paushkin S, Gubitz AK, Massenet S, Dreyfuss G (2002) The SMN complex, an assemblyosome of ribonucleoproteins. Curr Opin Cell Biol 14:305-312

Pitulescu ME, Schmidt I, Benedito R, Adams RH (2010) Inducible gene targeting in the neonatal vasculature and analysis of retinal angiogenesis in mice. Nat Protoc 5:1518-1534

Reddy S, Devlin R, Menaa C, Nishimura R, Choi SJ, Dallas M, Yoneda $\mathrm{T}$, Roodman GD (1998) Isolation and characterization of a cDNA clone encoding a novel peptide (OSF) that enhances osteoclast formation and bone resorption. J Cell Physiol 177:636-645

Rogers DC, Fisher EM, Brown SD, Peters J, Hunter AJ, Martin JE (1997) Behavioral and functional analysis of mouse phenotype: SHIRPA, a proposed protocol for comprehensive phenotype assessment. Mamm Genome 8:711-713
Schneider CA, Rasband WS, Eliceiri KW (2012) NIH Image to ImageJ: 25 years of image analysis. Nat Methods 9:671-675

Schrank B, Gotz R, Gunnersen JM, Ure JM, Toyka KV, Smith AG, Sendtner M (1997) Inactivation of the survival motor neuron gene, a candidate gene for human spinal muscular atrophy, leads to massive cell death in early mouse embryos. Proc Natl Acad Sci USA 94:9920-9925

Shanmugarajan S, Swoboda KJ, Iannaccone ST, Ries WL, Maria BL, Reddy SV (2007) Congenital bone fractures in spinal muscular atrophy: functional role for SMN protein in bone remodeling. $\mathrm{J}$ Child Neurol 22:967-973

Sirkis DW, Edwards RH, Asensio CS (2013) Widespread dysregulation of peptide hormone release in mice lacking adaptor protein AP-3. PLoS Genet 9:e1003812

Sparks AB, Hoffman NG, McConnell SJ, Fowlkes DM, Kay BK (1996) Cloning of ligand targets: systematic isolation of SH3 domaincontaining proteins. Nat Biotechnol 14:741-744

Sul OJ, Ke K, Kim WK, Kim SH, Lee SC, Kim HJ, Kim SY, Suh JH, Choi HS (2012) Absence of MCP-1 leads to elevated bone mass via impaired actin ring formation. J Cell Physiol 227:1619-1627

Szymkiewicz I, Destaing O, Jurdic P, Dikic I (2004) SH3P2 in complex with $\mathrm{Cbl}$ and Src. FEBS Lett 565:33-38

Tanimura S, Hashizume J, Kurosaki Y, Sei K, Gotoh A, Ohtake R, Kawano M, Watanabe K, Kohno M (2011) SH3P2 is a negative regulator of cell motility whose function is inhibited by ribosomal S6 kinase-mediated phosphorylation. Genes Cells 16:514-526

Tanimura S, Hashizume J, Arichika N, Watanabe K, Ohyama K, Takeda K, Kohno M (2016) ERK signaling promotes cell motility by inducing the localization of myosin $1 \mathrm{E}$ to lamellipodial tips. J Cell Biol 214:475-489

Tong S, Zhou H, Gao Y, Zhu Z, Zhang X, Teng M, Niu L (2009) Crystal structure of human osteoclast stimulating factor. Proteins $75: 245-251$

van't Hof RJ (2012) Analysis of bone architecture in rodents using microcomputed tomography. Methods Mol Biol 816:461-476

van't Hof RJ, Ralston SH (1997) Cytokine-induced nitric oxide inhibits bone resorption by inducing apoptosis of osteoclast progenitors and suppressing osteoclast activity. J Bone Miner Res 12:1797-1804

Vinayagam A, Stelzl U, Foulle R, Plassmann S, Zenkner M, Timm J, Assmus HE, Andrade-Navarro MA, Wanker EE (2011) A directed protein interaction network for investigating intracellular signal transduction. Sci Signal 4:rs8

Volgyi B, Chheda S, Bloomfield SA (2009) Tracer coupling patterns of the ganglion cell subtypes in the mouse retina. J Comp Neurol 512:664-687

Wenzel J, Ouderkirk JL, Krendel M, Lang R (2015) Class I myosin Myo1e regulates TLR4-triggered macrophage spreading, chemokine release, and antigen presentation via MHC class II. Eur J Immunol 45:225-237

Yang M, Crawley JN (2009) Simple behavioral assessment of mouse olfaction. Curr Protoc Neurosci 8:8-24

Yokosuka M, Matsuoka M, Ohtani-Kaneko R, Iigo M, Hara M, Hirata K, Ichikawa M (1999) Female-soiled bedding induced fos immunoreactivity in the ventral part of the premammillary nucleus (PMv) of the male mouse. Physiol Behav 68:257-261 